\title{
O olhar do Papa Francisco para o Sul Global: uma análise sobre o diálogo entre o Vaticano e a República Popular da China
}

The Pope Francis' view to Global South: an analysis about the dialogue between Vatican and Republic of China

La mirada del Papa Francisco para el Sur Global: un análisis sobre el diálogo entre el Vaticano y la República Popular China

Ana Beatriz da Costa Mangueira ${ }^{1}$

DOI: 10.5752/P.1809-6182.2019v13n3p7

Recebido em: 24 de agosto de 2018 Aceito em: 09 de junho de 2019

\section{Resumo}

Este artigo analisa a atuação do Papa Francisco no diálogo entre o Vaticano e a República Popular da China nos últimos dois anos do atual pontificado. Observa-se que o olhar do pontifice para o Sul Global colabora com esse diálogo, que sofreu ruptura na década de 1950.

Palavras-chave: Papa Francisco. Vaticano. República Popular da China.

\begin{abstract}
This paper aims to analyze the Pope Francis influence on the dialogue between the Vatican and the People's Republic of China in the last two years. It is observed that the Pope's view to Global South cooperates with this dialogue, which has been interrupted since 1950s.

Keywords: Pope Francis. Vatican. Republic of China.

Resumen

Este artículo examina la actuación del Papa Francisco en el diálogo entre el Vaticano y la República Popular China en los últimos dos años del pontificado actual. Se observa que la mirada del pontifice para el Sur Global contribuye para este diálogo, que sufrió una ruptura en la década de 1950.

Palabras-clave: Papa Francisco. Vaticano. República Popular China.
\end{abstract}

\footnotetext{
1 Mestre em Relações Internacionais pelo Programa de Pós-Graduação em Relações Internacionais da Universidade Estadual da Paraíba (PPGRI-UEPB). João Pessoa/Brasil. ORCID: https://orcid.org/0000-0002-3246-0058.
} 


\section{Considerações Iniciais}

Durante parte significativa da evolução dos estudos sobre relaçóes internacionais, acreditou-se que com o advento do secularismo a religiâo perdeu a sua atuação política no mundo. Para a visão secular, a influência global da Igreja Católica, por exemplo, se extinguiu (HAYNES, 2016, p. 28). Mas ao observar as atuaçôes dessa instituição e do seu líder no cenário internacional, se verifica justamente o oposto, pois esses atores continuam mantendo diálogos com outros, inclusive com os Estados. Além disso, para Graham (2013, p. 32), as últimas décadas foram marcadas pelo "ressurgimento do ativismo religioso" que vem acontecendo no mundo todo, especialmente no Sul Global, o que se opóe à previsão secular de que a religiáo vinha perdendo impacto público e político. Turzi (2013, p. 19) entende ser necessário considerar a relevância dos atores religiosos, marginalizados pela ciência com o surgimento da secularização. Omitir a religião dos debates de Política Internacional pode prejudicar a compreensão de questóes importantes para a área, como as atuaçóes do Papa, relevante para a condução da diplomacia do Vaticano no cenário mundial.

Desde a chegada do Papa Francisco ao pontificado no ano 2013, se observa que a diplomacia do Vaticano experimenta significativas transformaçóes. $\mathrm{O}$ mundo tem testemunhado a aproximação da Santa Sé com países que antes não dialogavam com essa entidade, especialmente aqueles do Oriente Médio e da Ásia (VUKIĆEVIĆ, 2015, p. 70). Argumenta-se que o posicionamento do atual pontífice influencia essas modificaçóes, uma vez que escolheu alterar o foco das relaçóes do Vaticano, antes voltado ao Ocidente e ao "centro do mundo", para a "periferia” (CARLETTI, 2015, p. 218). A visão global do Papa Francisco, bem como suas origens e suas experiências como clérigo influenciam o modo como conduz a diplomacia da Santa Sé. Para Almeida (2013, p. 299), o atual Papa tem como propósito estabelecer a comunicação global. Assim, o pontífice pode contribuir para transformaçóes de tópicos mundiais que envolvem a Igreja Católica, sobretudo os que são considerados mais delicados para a instituição, como o que se refere aos dissensos entre a República Popular da China (RPC) e o Vaticano.

As raízes da ruptura do diálogo entre a China e o Vaticano remetem à década de 1940, quando o Partido Comunista Chinês (PCC) chegou ao poder, e "o papado, pelas suas estreitas ligaçóes com o Ocidente, e pela declarada oposição ao comunismo, foi considerado como uma ameaça para a soberania chinesa" (CARLETTI, 2008, p. 12). Com efeito, a Igreja Católica na China foi dividida em Igreja patriótica e Igreja clandestina: a primeira se declarou a favor do Estado, aceitando ser controlada por ele; e a segunda continuou ao lado do Vaticano e do Ocidente, rejeitando as condiçóes impostas pelo governo comunista chinês (TSE-HEI LEE, 2007, p. 279). Essa divisão ainda perdura, sendo uma problemática no sentido do reconhecimento pelo Vaticano de bispos nomeados pela China, mas que são considerados ilegítimos para a Igreja.

Nos últimos dois anos do atual pontificado, o diálogo sino-vaticano é alvo de discussôes dentro da arena de religião e de relaçóes internacionais. Desde 2013 os laços entre o Vaticano e a China começaram a se estreitar. Nesse ano, Papa Francisco "entrou em contato com a China trocando notas de congratulaçóes com o Secretário Geral do PCC, Xi Jinping em sua pos- 
se" (LEUNG; WANG, 2016, p. 14). De acordo com Leung e Wang (2016), embora em 2015 o governo chinês tenha endurecido o controle sobre as religiôes ${ }^{2}$, notou-se uma abertura para negociações entre o Papa Francisco e o governo no ano seguinte sobre a questão que constantemente inflamou o relacionamento da China com a Igreja Católica: a nomeação de bispos. Para Faggioli (2018, s/p), as atuais "negociaçôes do Vaticano com a China representam o esforço diplomático mais importante da Santa Sé em décadas". Logo, questiona-se como o olhar do Papa Francisco, voltado para o Sul Global, contribui para as relaçóes sino-vaticanas.

Para nortear a discussão, o artigo está estruturado em duas seçôes: a primeira parte contextualiza a ruptura de relaçóes entre a China e o Vaticano, compreendendo que o advento do PCC representa uma das variáveis causais para a interrupção dessas relaçôes; a segunda parte se debruça sobre a figura do Papa Francisco, entendendo o seu olhar direcionado ao Sul Global como via de transformação em questôes que envolve a Igreja Católica no cenário internacional. Por fim, realiza-se uma reflexão sobre os esforços do Papa Francisco e do governo chinês no estabelecimento de um acordo sobre os bispos na China, e sobre a posição do Papa nesse cenário.

\section{A Igreja Católica e a RPC: contextos e perspectivas}

A presença do cristianismo na China é secular e chama a atenção pelo modo como os princípios cristãos e ocidentais agitaram a esfe-

2 As religiôes na China são reguladas pelo PCC, cujo principal objetivo consiste em manter o poder político (KUAN, 2012, p. 158). Uma das exigências do Partido para que uma religião seja reconhecida pelo Estado é o desempenho dela na vida pública (KUAN, 2012, p. 158). ra política chinesa (CARLETTI, 2008, p. 14). $\mathrm{Na}$ década de 1940, quando o PCC chegou ao poder, o governo chinês expressou desconfiança com representantes da Igreja Católica no país. Para Carletti (2008, p. 11), essa desconfiança é fruto das circunstâncias do período colonial europeu na China, quando as potências ocidentais desrespeitaram a soberania chinesa. Ademais, a forma como a doutrina cristá católica era colocada em prática desconsiderava a cultura e os costumes chineses (CARLETTI, 2008, p. 12). Com esses acontecimentos, "todos os estrangeiros tornaram-se, aos olhos dos chineses, automaticamente inimigos, incluindo os missionários" (CARLETTI, 2008, p. 12).

Nessa acepção, o Estado chinês passou a exigir que os católicos participassem de atividades religiosas apenas em igrejas reconhecidas pelo governo (YIK- YI CHU, 2012, p. 107). O Vaticano sempre foi contra a política chinesa de interferência em assuntos religiosos (LEUNG; WANG, 2016, p. 5), uma das motivaçóes para que o relacionamento da Igreja Católica com a RPC fosse marcado por perseguiçóes, resistência e ruptura. A posição anticomunista da Santa Sé resultou em expulsóes de clérigos contrários às diretrizes e práticas comunistas na região (CARLETTI, 2008, p. 83). Com efeito, na década de 1950 foi criada a Associação Patriótica Católica Chinesa (APCC), representando o primeiro traço da divisão da Igreja Católica na China. A proposta da APCC era a de continuar seguindo os preceitos da Igreja Católica, composta por clérigos, mas também a de apoiar o governo comunista, que era contra a hegemonia ocidental (VUKIĆEVIĆ, 2015, p. $75)$. Por sua vez, os católicos e o clero que divergiam da Igreja Patriótica foram considerados pelo governo um movimento clandestino, constituindo a "Igreja Católica Clandestina na China", ligada ao Vaticano (TURZI, 2013, p. 24). 
A divisão da Igreja na China provocou dissensos em questóes que para o Vaticano deveriam ser somente de sua responsabilidade, como a nomeação de bispos, tarefa exclusiva dessa entidade, mas que passou a ser executada pelo PCC (LEUNG; WANG, 2016, p. 5). Apesar das divergências entre o Vaticano e a RPC, no governo de Deng Xiaoping surgiu a possibilidade de mudanças em relação à Igreja Católica na China, pois nesse período o país experimentava transformações sociais. A política de "portas abertas", implementada no governo de Deng Xiaoping, possibilitou, na década de 1970, a reabertura de Igrejas Católicas na China que se encontravam fechadas (CARLETTI, 2008, p. 127). Nesse contexto, a Santa Sé visava se aproximar da Igreja Católica na RPC, tentativa que fracassou (LEUNG; WANG, 2016). Como consequência desse insucesso, a Santa Sé buscou dialogar com os católicos de Taiwan e Hong Kong (LEUNG; WANG, 2016, p. 8), aproximação vista com desconfiança pelas autoridades chinesas.

O primeiro obstáculo para as relaçóes diplomáticas entre a Santa Sé e a RPC reside justamente no fato dessa entidade reconhecer Taiwan, questão relevante para a RPC, devido ao seu histórico conflituoso com Taiwan ${ }^{3}$ (VUKIĆEVIĆ, 2015, p. 75). Por isso, pode-se afirmar que Taiwan representa "um elemento que influencia diretamente as prolongadas negociaçóes sino-vaticanas" (LEUNG; WANG, 2016, p. 15). Outro obstáculo ao reatamento de laços entre China e Vaticano consiste na intenção de Pequim em designar bispos, o que é

3 Durante a Revolução chinesa na década de 1940, o conflito entre Partido Nacionalista e Partido Comunista levou Chiang Kai-shek fugir para Taiwan junto com seus aliados quando o PCC chegou ao poder (VUKIĆEVIĆ, 2015, p. 75). Nesse período, Taiwan se declarou um país e Kaiseu líder, obtendo o reconhecimento de alguns atores internacionais, como a Santa Sé (CARLETTI, 2008, p. 10). considerado um desrespeito à soberania do Vaticano (TURZI, 2013, p. 24). Por isso a Igreja Católica na China ainda continua dividida, e os laços entre o Vaticano e a RPC rompidos desde 1951. Essas relaçôes sofrem atualmente transformações desde quando Papa Francisco chegou ao papado, mas em especial nos últimos dois anos, contexto em que o governo chinês se mostrou mais aberto ao diálogo com o Vaticano.

Argumenta-se que Papa Francisco representa o principal elo entre o Vaticano e a China. Segundo Turzi (2013), por ser jesuíta, na condução do diálogo sino-vaticano o pontífice é tanto simbólico quanto significativo, tendo em vista que os jesuítas possuem uma história longa com a China. Para esse autor, "o carisma jesuíta busca construir pontes, adaptar e trabalhar com a realidade, em vez de se impor contra ela" (TURZI, 2013, p. 24). Observa-se que Papa Francisco busca justamente construir uma ponte entre o Vaticano e a China com o principal objetivo de unir a Igreja no país, dividida há mais de cinco décadas (SUMMARY OF BULLETIN, 2018).

As negociaçóes entre Papa Francisco e a China têm provocado divergências na Instituição católica, tendo em vista o histórico de perseguiçóes a clérigos da Igreja e a nomeação de bispos feita pelo PCC (CARLETTI, 2008). A "oposição significativa do hemisfério ocidental" à abertura do pontífice para um diálogo com a RPC não impediu que o Papa se mantivesse firme na busca pelo objetivo pastoral de unir a Igreja naquele país (FAGGIOLI, 2016). O primeiro passo para uma reconciliação pode ser atribuído a assinatura do Acordo Santa Sé-China de 2018 atinente à questão dos bispos. $\mathrm{Na}$ mensagem aos católicos chineses divulgada em 28 de setembro de 2018, o pontífice declarou que esse é um momento significativo para a vida da Igreja, especialmente porque a presença da instituição na China é 
marcada por tensôes (FAGGIOLI, 2016). Nessa mensagem, Papa Francisco expressou o seu respeito pela cultura chinesa, afirmando que o povo chinês resistiu as adversidades, abraçou as diferenças e se demonstrou receptivo a mensagem cristã (SUMMARY OF BULLETIN, 2018).

O fator religioso se encontra presente náo somente na mensagem do Papa enviada aos chineses, mas também no seu olhar estratégico para o Sul Global com o intuito de estabelecer um equilíbrio entre "centro" e "periferia" no quadro de relaçôes do Vaticano (CARLETTI, 2015, p. 218). Essa é um sinal de que a religião está ativa na vida pública e política, seja em nível local, nacional e/ou global (GRAHAM, 2013). A preferência do pontífice é por um mundo multipolar "onde as diferenças ao invés de dividir podem acrescentar", rumo a um mundo menos desigual (CARLETTI, 2015, p. 233). Tendo isso em vista, a seção subsequente se dedica à reflexão sobre o papel do Papa Francisco na construção de uma ponte que aproxime a RPC e o Vaticano.

\section{Papa Francisco e seu projeto global: construindo pontes}

O líder da Igreja Católica, o Papa, é considerado um importante ator por vários motivos, um deles relacionado ao fato desse indivíduo representar tanto o condutor da Instituição Católica, quanto o chefe do "Poder Executivo do Estado do Vaticano" (TURZI, 2013, p. 30). Graças a sua liderança e a sua posição como ator religioso nas relações internacionais, o Papa pode exercer o chamado soft power ${ }^{4}$ (HAYNES,

\footnotetext{
4 Soft power, para Joseph Nye Jr. (1990, p. 166), consiste em um poder que um ator exerce, fazendo com que outros atores concordem com determinada ação ou política. Segundo Carletti (2015, p. 221), a Igreja Católica age com o soft power por meio de várias igrejas que se encontram pelo mundo.
}

2016), condição possível de ser executada por diálogos, por exemplo, com outros atores internacionais. As mensagens, decisões e ações do Papa representam três elementos que podem gerar impactos significativos em matérias que envolvam a Igreja Católica no cenário internacional. Portanto, entende-se que o soft power exercido pelo pontífice sucede por meio desses três elementos, já que ele é considerado líder religioso influente nas relaçóes internacionais.

Desde sua chegada ao pontificado, Papa Francisco busca gradativamente aproximar o Vaticano com outras regióes do mundo que não sejam parte apenas do Ocidente. Ao conferir maior importância à periferia (TURZI, 2013, p. 21), o pontífice promove discussóes sobre as desigualdades sociais e, ainda, facilita a aproximação do Vaticano com países não-ocidentais.

A conduta do Papa Francisco na mudança de foco do mundo ocidental e europeu para a "periferia do mundo" pode ser associada ao fato de ser o primeiro Papa não europeu (CARLETTI, 2015). É possível observar que o comportamento e as experiências do Papa Francisco, durante a sua trajetória de vida até chegar ao pontificado, traduzem algumas características particulares de sua pessoa como indivíduo e como clérigo: faz parte da comunidade jesuíta e sempre possuiu contato diário com o povo (TURZI, 2013). Esses fatores influenciam a forma como o pontífice busca conduzir as decisões do Vaticano. Conforme Carletti (2015, p. 233), "as experiências de vida do Papa Francisco como um cidadão da periferia do mundo colaboram com sua visão da periferia para o centro, e não o contrário como foi feito com os outros papas".

A antiga política do Vaticano, de manter relacionamentos mais estreitos com o Ocidente e com o "centro do mundo", é alterada à me- 
dida que o deslocamento ideológico do Papa Francisco se volta "mais às periferias do planeta que aos centros tradicionais de poder" (CARLETTI, 2015, p. 233). Isso pôde ser notado na cúria romana ${ }^{5}$, quando ao invés de priorizar cardeais de origem europeia, Papa Francisco escolheu cardeais de outros continentes, como África, Ásia, América Central e América do Sul (CARLETTI, 2015, p. 231).

A reflexão sobre as características do Papa Francisco, e sobre sua extensão global mais direcionada à periferia do planeta e ao Oriente, condiciona a discussão do seu importante papel na resolução de algumas divergências da Igreja, como a que se refere à divisão da Igreja na China. De acordo com Turzi (2013, p. 24), a maior fronteira ainda hoje da Igreja Católica é com a China. Apesar disso, acredita-se que o pontífice é capaz de influenciar o cenário de ruptura entre o Vaticano e a RPC. Para tanto, Vukićević (2015, p. 73) acredita que "a diplomacia papal precisa ser complexa e equilibrada para atingir seus objetivos", buscando melhorar também a imagem da Igreja Católica em todo o mundo.

Segundo Turzi (2013, p. 23), Papa Francisco busca fazer jus ao próprio sentido da palavra 'pontífice', criando pontes entre pastores e fiéis, entre credos e entre países. Argumenta-se, aqui, que esse é o principal objetivo do líder católico em relação à RPC: criar uma ponte entre o Vaticano e o país, bem como entre a Igreja que se encontra dividida na China. As variáveis que influenciaram a ruptura de relaçóes do Vaticano com a China são históricas, como foi possível entender na seção anterior. No que diz respeito a essas relaçóes, a nomeação de bispos

5 A cúria romana diz respeito ao corpo da Igreja que ajuda o papa na administração da instituição. Nesse contexto, o pontífice decide sobre a nomeação e a substituição dos indivíduos que poderão fazer parte desse corpo (VATICAN, on-line). constantemente representou um ponto delicado, especialmente por causa da divisão da Igreja Católica no país declaradamente comunista, e, portanto, pelo náo reconhecimento da Igreja Patriótica pelo Vaticano.

As nomeaçôes de bispos são de significativa importância para a Igreja Católica, uma vez que está ligada à política da instituição de manter hierarquias e doutrinas (FAGGIOLI, 2018). Após a Segunda Guerra Mundial, "as nomeaçóes dos bispos foram consideradas uma questão importante para as relaçóes diplomáticas entre o Vaticano e os países sob o domínio comunista" (FAGGIOLI, 2018, s/p). Na China, por exemplo, os bispos escolhidos pelo governo não eram reconhecidos pela Igreja. Por esse motivo, Vukićević (2015, p. 76) entende que a questão da ordenação dos bispos na China ainda segue como um dos tópicos mais sensíveis no diálogo entre o Vaticano e esse país. Esse é um tema que está no centro do hodierno debate sobre as relaçóes sino-vaticanas, tendo em vista que as negociaçóes acerca das nomeaçóes de bispos, que não eram certificadas pela Igreja, vêm progredindo. Para Pequim, o reconhecimento dos bispos pelo Vaticano que foram escolhidos pelo governo representaria um passo significativo para o reatamento de laços entre a China e o Vaticano (LEUNG; WANG, p. 9).

A temática que envolve o Vaticano e a RPC chama a atenção daqueles que conhecem a história do relacionamento desses dois atores, caracterizado por dissensos. Argumenta-se que o basilar projeto global do Papa Francisco de construir pontes é significativo para o fim das tensóes entre o país e a entidade. Faggioli (2018) afirma que

Aqueles que acreditam neste possível avanço entre o Vaticano e a China hoje sabem que já há uma longa história do cristianismo na 
China, com a qual a Igreja Católica global precisa estar mais diretamente em contato. Esta é uma parte integrante da visão do Papa Francisco para uma Igreja Católica verdadeiramente global, a serviço de toda a humanidade e da paz mundial (FAGGIOLI, 2018, s/p).

O olhar do Papa Francisco voltado ao Sul Global transforma a diplomacia do Vaticano e possibilita o deslocamento de um cenário de ruptura com a China para um cenário de reconciliação. O diálogo, que vinha acontecendo de forma lenta e gradual, avança com o Acordo Provisório Santa Sé-China, assinado em setembro de 2018 (SICSI, 2018). Após a assinatura desse acordo, Papa Francisco afirmou ser necessária a boa vontade de ambas as partes para que o referido acordo tenha êxito (SUMMARY OF BULLETIN, 2018). O pontífice ressaltou que o Acordo Provisório pode contribuir na escritura de um "novo capítulo da Igreja Católica na China”, pois, pela primeira vez durante a trajetória do diálogo sino-vaticano, pôde se estabelecer uma cooperação (SUMMARY OF BULLETIN, 2018, s/p).

\section{Considerações Fincis}

A religiáo exerce influência global e pode definir o relacionamento entre atores internacionais, como é o caso do diálogo entre China e Vaticano (GRAHAM, 2013). A ruptura dos laços sino-vaticanos possui caráter político e religioso, e foi com a fundação da APCC que as "divergências entre uma parte da Igreja Católica chinesa e o Vaticano" foram oficializadas (CARLETTI, 2008, p. 90). Para Tse-Hei Lee (2007, p. 291), a trajetória da divisão da Igreja Católica nesse país sempre foi um período doloroso para os chineses que possuem sua "fé expressa de duas maneiras diferentes". Segundo o autor, a esperança de futuras reconciliações também sempre esteve presente. A unidade da Igreja na China parece se aproximar cada vez mais com a presença do Papa Francisco no diálogo entre a RPC e o Vaticano. O pontífice, que opta pelo deslocamento ideológico do centro para as "periferias do mundo político e eclesial" (CARLETTI, 2015, p. 236), atua politicamente seguindo a sua religiosidade. Portanto, a visão secular sobre a separação entre política e religiáo perde espaço, aqui, para a perspectiva pós-secular, que considera a importância da religião na vida pública e nas relaçóes internacionais (GRAHAM, 2013).

$\mathrm{Na}$ mensagem conduzida aos católicos chineses e à Igreja Universal em setembro de 2018, após a assinatura do Acordo Provisório Santa Sé-China, Papa Francisco afirmou estar convencido de que a reaproximação "só pode ser autêntica e frutífera se ocorrer através da prática do diálogo para construir um futuro comum de harmonia sublime" (SUMMARY OF BULLETIN, 2018, s/p). O pontífice aconselhou os católicos chineses a serem bons cidadãos, amarem sua pátria e servirem seu país com honestidade, demonstrando o seu respeito ao povo chinês, à sua história e cultura. Segundo o Papa, os objetivos da Igreja com esse acordo são 'espirituais e pastorais', buscando contribuir para a unidade da Igreja na China, que foi dividida no passado (SUMMARY OF BULLETIN, 2018). Para atingir esses objetivos, o pontífice entende ser necessário tratar de assuntos concernentes a nomeação de bispos, uma das principais questôes que impedia a reaproximação entre a China e o Vaticano. Por isso, um acordo entre o Papa e Pequim sobre esse tópico parecia ser difícil de acontecer (TURZI, 2013, p. 25), mas o Acordo Provisório Santa Sé-China demonstra que a reconciliação é possível. Papa Francisco, que é autoridade máxima da 
Igreja e possui a palavra final sobre o assunto no Vaticano já demonstrou estar aberto para um diálogo (LEUNG; WANG, 2016).

A imagem carismática do Papa Francisco coloca-o em "uma boa posição para as negociaçôes na diplomacia inter-civilizacional que continua a ser uma parte importante dos assuntos da Santa Sé" (VUKIĆEVIĆ, 2015, p. 76). O atual líder da Igreja Católica busca mudar a política do Vaticano de manter relaçóes apenas com o Ocidente para uma política de reaproximação com o Oriente, e "já fez muito para reparar a imagem da Santa Sé aos olhos do mundo e torná-la mais ativa e presente nas relaçóes internacionais" (VUKIĆEVIĆ, 2015, p. 78). O projeto global do Papa com seu olhar voltado ao Sul do mundo tem como principal objetivo equilibrar 'centro' e 'periferia' nas questóes que concernem ao Vaticano (CARLETTI, 2015, p. 231). O pontífice reconhece a importância da diplomacia e do diálogo como meios de transformação para a união da Igreja. Por sua vez, o olhar do líder católico para o Sul Global se manifesta como uma das ferramentas necessárias para a unidade da Igreja na China e para a reaproximação entre o país e o Vaticano.

\section{Referências}

ALMEIDA, Ronaldo de. A visita de Francisco e a abertura do compasso. Estudos de Religiáo, v. 27, n. 2, p. 297-303, jul./ dez. 2013.

CARLETTI, Anna. A abertura da China ao mundo e as suas relaçôes com o Vaticano de Joáo Paulo II. In.: Diplomacia e Religiáo: encontros e desencontros nas relações entre a Santa Sé e a República Popular da China de 1949 a 2005. Brasília: Funag, 2008, cap. 1 e 3.

CARLETTI, Anna. Do centro às periferias: o deslocamento ideológico da diplomacia da Santa Sé com o Papa Francisco. Austral: Revista Brasileira de Estratégia e Relaçóes Internacionais, v. 4, n. 7, p. 218-239, 2015.

FAGGIOLI, Massimo. China-Vatican talks uphold historical legacy. Global Times, 2018. Disponível em: http://www.globaltimes.cn/content/1090048.shtml. Acesso em: 05 mar. 2018.
GRAHAM, Elaine. Between a Rock and a Hard Place: Public Theology in a Post-Secular Age. London: SCM Press, 2013. HAYNES, Jeffrey. Religião nas Relaçóes Internacionais: Teoria e Prática. In.: CARLETTI, Anna; FERREIRA, Marcos Alan S. V. (org.). Religiáo e Relaçóes Internacionais: Dos Debates Teóricos ao Papel do Cristianismo e do Islã. Curitiba: Juruá Editora, 2016, p. 20-49.

KUAN, Hsin-chi. Religion and Politics in China. Universal Rights in a World of Diversity: The Case of Religious Freedom. Pontifical Academy of Social Sciences, acta 17, p. 155-192, 2012.

LEUNG, Beatrice; WANG, Marcus J. J. Sino-Vatican Negotiations: problems in sovereign right and national security. Journal of Contemporary, China, v. 25, n. 99, p. 467-482, fev. 2016.

NYE, Joseph, Jr. Soft Power. Foreign Policy, n. 80, p. 153171, outono 1990.

SICSI, Francesco. China-Santa Sé: um acordo histórico. Revista Instituto Humanitas Unisinos. 2018. On-line. Disponível em: http://www.ihu.unisinos.br/78-noticias/583030-china-santa-se-um-acordo-historico. Acesso em: 30 nov. 2018.

SUMMARY OF BULLETIN. Message of Pope Francis to the Catholics of China and to the Universal Church, 26 set.2018. Holy See Press Office. 2018. Disponível em: https:// press.vatican.va/content/salastampa/en/bollettino/pubblico/2018/09/26/180926b.html. Acesso em: 28 nov. 2018.

TSE-HEI LEE, Joseph. Christianity in Contemporary China: an update. Journal of Church and State, v. 49, n. 2, p. 277304, abr. 2007.

TURZI, Mariano. El Papa Del Tercer Mundo. Foreign Affairs Latinoamérica, n. 3, v. 13, p. 19-25, set. 2013.

VATICAN. A cúria romana. Disponível em: http://www.vatican.va/roman_curia/index_po.htm. Acesso em: 22 de abril de 2018.

VUKIĆEVIĆ, Boris. O Papa Francisco e os desafios de uma diplomacia inter-civilizacional. Revista Brasileira de Política Internacional, n. 58, v. 2, p. 65-79, 2015.

YIK- YI CHU, Cindy. Chinese Society and Catholicism. In.: The Catholic Church in China: 1978 to the present. New York: Palgrave Macmillan, 1 ed, 2012, p. 103-119. 